\title{
Using Active Learning with Smart Board to Enhance Primary School Students' Higher Order Thinking Skills in Data Handling
}

\author{
Abdul Halim Abdullah ${ }^{1, *}$, Soh Hon Mun ${ }^{1}$, Mahani Mokhtar ${ }^{1}$, Zakiah Mohamad Ashari, \\ Nurul Farhana Jumaat ${ }^{1}$, Dayana Farzeeha Ali ${ }^{1}$, Norazrena Abu Samah ${ }^{1}$, \\ Muhammad Sani Abdurrahman ${ }^{2}$ \\ ${ }^{1}$ School of Education, Faculty of Social Sciences and Humanities, Universiti Teknologi, Malaysia \\ ${ }^{2}$ Department of Mathematics, Waziri Umaru Federal Polytechnic, Kebbi State, Nigeria
}

Received May 17, 2020; Revised June 30, 2020; Accepted July 20, 2020

\section{Cite This Paper in the following Citation Styles}

(a): [1] Abdul Halim Abdullah, Soh Hon Mun, Mahani Mokhtar, Zakiah Mohamad Ashari, Nurul Farhana Jumaat, Dayana Farzeeha Ali, Norazrena Abu Samah, Muhammad Sani Abdurrahman, "Using Active Learning with Smart Board to Enhance Primary School Students' Higher Order Thinking Skills in Data Handling," Universal Journal of Educational Research, Vol. 8, No. 10, pp. 4421-4432, 2020. DOI: 10.13189/ujer.2020.081009.

(b): Abdul Halim Abdullah, Soh Hon Mun, Mahani Mokhtar, Zakiah Mohamad Ashari, Nurul Farhana Jumaat, Dayana Farzeeha Ali, Norazrena Abu Samah, Muhammad Sani Abdurrahman (2020). Using Active Learning with Smart Board to Enhance Primary School Students' Higher Order Thinking Skills in Data Handling. Universal Journal of Educational Research, 8(10), 4421-4432. DOI: 10.13189/ujer.2020.081009.

Copyright $(2020$ by authors, all rights reserved. Authors agree that this article remains permanently open access under the terms of the Creative Commons Attribution License 4.0 International License

\begin{abstract}
Data Handling is an important topic in the Mathematics Primary Curriculum as it brings the real world of seeing data to students. However, the assessments of PISA and TIMSS indicated that the level of Malaysian students' performance and Higher Order Thinking Skills (HOTS) in Data Handling is declining. Thus, this study was designed to develop active learning instructions using smart board (ALuSB programme) and to evaluate its effectiveness in enhancing HOTS among Malaysian students in Data Handling. The study was carried out in two stages; the design and development of ALuSB programme stage based on ADDIE model and the evaluation stage to see the enhancement of HOTS in Data Handling. The research design adopted for this study was a pre-test post-test quasi-experimental design using non-equivalent control group. Quantitative and qualitative data were collected for analyses. The quantitative data was analysed using One-way ANOVA to evaluate the mean differences between the treatment groups whereas a post hoc test was further used to determine precisely which mean differences were significant and visa-versa among all the three groups. Additionally, the qualitative data was analysed using thematic analysis. The findings in this study
\end{abstract}

indicated that ALuSB programme has the potential to improve students' performance and HOTS in Data Handling. Students also demonstrated increase in their ability to carry out a procedure, differentiate and organise data, make judgments and create a table or graph, making the ALuSB programme suitable to be applied in schools as it can effectively help students to enhance their HOTS.

Keywords Active Learning, Smart Board, Higher Order Thinking Skills (HOTS), Data Handling

\section{Introduction}

Data Handling is a significant topic in Mathematics Curriculum in Malaysia and therefore it is introduced to primary school students. Data Handling involves the processes of organising and reducing, describing, analysing and interpreting as well as representing a set of data. It is an important subtopic of statistics which brings a learner out into the real-world of seeing data, reflecting upon it socially or individually, and make decisions from it 
[1]. However, the assessments of PISA and TIMSS indicated that Malaysian students performed poorly on the topic of Data Handling which was below the international average. Results showed that Malaysian students in the urban and rural areas performed moderately in the PISA assessment [2] whereas the average score of TIMSS assessment fell from 505 in 2003 to 429 in 2011 [3].

It is crucial that any type of Data Handling should be given a real life context or problem solving approach to help build children's understanding of the purpose of Data Handling, and to help them recognise when to use certain Data Handling approaches when faced with problems. This aspect must be taken into consideration in Data Handling lessons especially for year five primary school students as the Malaysian Mathematics Integrated Curriculum for Year Five encompasses most of the important skills of Data Handling. It is expected that year five primary school students would be able to understand and apply the knowledge of average, understanding the vocabulary relating to data organisation in graphs, as well as organising and interpreting data from tables and charts [4]. Therefore, it is important for teachers to ensure that students understand the concept of Data Handling during their primary years.

The inculcation of HOTS in Malaysian schools is a challenging task since the teaching and learning process in Malaysia focuses on lower-level cognitive activities [5-10]. Preliminary report of a study highlighted in Malaysian Education Blueprint 2013-2025 showed that primary school mathematics teachers relied on the traditional "chalk and talk" method of teaching and learning and did not adequately engage students in constructive thinking. Most importantly, the learning focus is still on achieving surface-level content understanding or directed at recalling of facts rather than cultivating HOTS [11]. Hence, teachers prefer to use thinking skills such as memorising, recalling and understanding because in most classrooms, HOTS receive none or little attention from students as well as teachers [12].

At present, Malaysia is undergoing a dramatic transformation in the local educational system. The UNESCO assessment noted that Malaysia was among the first few countries in the world to implement a strategic ICT plan for its education system in order to integrate the potential of ICT to enhance the depth of knowledge and increase the overall quality of education system in Malaysia [11]. One of the educational technology tools that has caught the attention of teachers in this recent year is the smart board [13]. Smart board was introduced by the MOE in Malaysia in 2004 [14]. Smart board combines all the functions of a computer, whiteboard and projector into a single system [15]. It is more than a computer, a projector or a screen [16] as it can be used to deliver instruction in visual, auditory and tactile learning [17].

Academic librarians found that integrating smart board into instruction sessions was able to facilitate active learning, which is an important component of contemporary instructions [18], as current students are active learners and traditional lecture may be increasingly out of touch with how students are learning to engage themselves with their world [19]. Students' active involvement in the learning process is vital for the mastery of skills such as critical thinking as well as contributing to their likelihood of programme completion $[20,21]$. Therefore, this study was conducted to help students to enhance their HOTS in Data Handling by integrating active learning with smart board.

\section{Research Objectives}

The objectives of this research were:

i. To design and develop active learning instruction using smart board (ALuSB programme) to enhance HOTS in Data Handling among students in Malaysian primary schools.

ii. To evaluate the effectiveness of the ALuSB programme in enhancing HOTS in Data Handling among students in Malaysian primary schools.

\section{Methodology}

The research design of this study was divided into two stages. Firstly, the activities in stage one were designed, developed and implemented based on ADDIE model (Analysis, Design, Development, Implementation, Evaluation). In this model, the first phase identified students' learning difficulties for each level of HOTS in Data Handling. The second phase was the designing of interactive lessons for ALuSB programme whereby the Smart Board as a teaching and learning interactive tool was integrated with the active learning model [22] consisting of learning activities that involved dialogue with self, dialogue with others, experience of doing and experience of observing. The third phase involved the development of interactive lessons with the use of the Smart Board to teach Data Handling. Finally, in the fourth phase, ALuSB programme was implemented on a group of 10 students over five weeks in the pilot study. Interviews were used to collect data to investigate the use of the ALuSB programme.

In the second stage, pre-test and post-test quasi-experimental design using non-equivalent control group design [23] were conducted to evaluate the effectiveness of the ALuSB programme in enhancing HOTS in Data Handling among students in a Malaysian primary school. Ninety students from the same population were split into three groups equally; two experimental groups (ALuSB programme and active learning instruction) and one control group (conventional learning method). This study was conducted for eight weeks where quantitative data were collected through pre-test and post-test whereas qualitative data was collected through 
student's interview.

The quantitative data in this research was analysed based on descriptive and inferential statistics using SPSS statistics version 23. One-way ANOVA test was used as it was found to be suitable for comparing three or more groups for statistical significance [24]. Then, in order to determine which mean differences were significant or vice versa, post hoc test was used [25]. Additionally, thematic analysis was used to analyse the qualitative data [26]. Research questions were used to group the findings of the interview and then were used to support the quantitative results.

\subsection{Samples Selected for the Study}

In this research, 90 students comprising 45 males and 45 females were selected from year five students in a Malaysian primary school to address the objectives of the study. The selection of the students was based on purposive sampling in which they are from medium performing groups with average academic achievement in mathematics.

\subsection{Research Instruments}

The following research instruments were employed in this study: ALuSB programme evaluation form, pretest and posttest, rubric, and interviews.

\subsubsection{ALuSB programme evaluation form}

The ALuSB programme evaluation form is used in this research for the students to evaluate the consequences of active learning instruction using a Smart Board. The ALuSB programme evaluation form uses Likert scale measurements which are modified according to the theoretical framework used in this study and from various reliable sources in Smart Board learning design. It is designed by the researchers based on the instrument for the Smart Board from [27], active learning from [28] and HOTS from [29]. The ALuSB programme evaluation form was validated by five experts who had experience designing the active learning evaluation form, had working experience in the field of research, as well as experience designing HOTS evaluation form. All the experts strongly agree that the questions in the ALuSB programme evaluation form are presented and organised in a logical manner, the questions have the capability to measure items of variables within a given time frame, instructions of the questions are clearly stated and the measurement scale of the questions is clear and suitable.

\subsubsection{Pre-test and post-test}

Pretest and posttest were used in this study to identify the development of students' learning through the scores and level of the cognitive domain in HOTS. The pretest is conducted before implementing the ALuSB programme while the posttest was conducted after implementing the ALuSB programme. Posttest was conducted six weeks after the pretest. Both tests have the same set of questions, eight performance test items with different sequence and values. The questions are designed based on the previous assessment features designed by PISA and TIMSS to assess students' HOTS with regards to the cognitive domain of Bloom's Taxonomy. Both tests undergoes experts' content validity and all the experts strongly agree with the items designed for the tests. They further stress that the design and development of HOTS items in both tests were suitable and based on the criteria of test content validity which were conformity, accuracy, clarity and suitability of the items. Additionally, the features of HOTS items were stimulus, multi-level thinking, non-conventional context, real situation in daily life, and non-repeating items as issued by the Malaysian Examination Board. The scores of the pre-test and post-test during the formative evaluation are collected and analysed using Statistical Package for the Social Sciences (SPSS) Statistics version 23 to calculate the internal consistency of both tests. The Cronbach's alpha of internal consistency for the pre-test was 0.885 meanwhile the Cronbach's alpha of internal consistency for the post-test was 0.975. Both results indicate a high level of internal consistency.

\subsubsection{Rubric}

A rubric is a multipurpose scoring guide for evaluating student performances and products [30]. It works in various ways to advance student learning in such a way that it makes the learning objectives clearer [31] and provide students with a tool for self-assessment as well as peer feedback [32]. Students are able to perform better and critique their performances when they know in advance the criteria for evaluating their performance. Rubrics also guide delivery and instructional design. The rubric for HOTS evaluation is modified based on the [33] revised taxonomy. Five scores represent different criteria of the assessment answers in the rubric for HOTS evaluation. The minimum score is zero, and the maximum score is four for each level of the cognitive domain in HOTS. The rubric for HOTS evaluation is validated by five experts who have experience in teaching HOTS in mathematics education. All the experts strongly agree with the items of pre-test and post-test and commented that the score for each criterion of the assessment answers in the rubric for HOTS evaluation is suitable to be used.

\subsubsection{Interviews}

Interviews are systematic ways of talking and listening to people, a way to collect data from individuals through conversations [34] as well as an effective method to gain information about the benefits of HOTS [35]. In this study, an in-depth one-on-one interview was conducted by the researchers during the stage one of the research design and after students' post-test during the research design stage 
two to support the findings from other instruments. An in-depth interview involves conducting intensive individual interviews with a small number of respondents to explore their perspectives on a particular idea, program or situation [36]. Structured interviews with ten open-ended questions are used in this study and five experts who have experience in teaching HOTS in mathematics education validate the questions used in the interview. All the experts strongly agree that the objective of the interview questions are stated clearly, the number of questions answered by the participants is suitable, the vocabulary level, language, structure of the interview questions are equivalent to the conceptual level of participants as well as the interview questions are capable of generating data that will be of value and practical use to the sectors concerned in the investigation. The interview involved ten students who use ALuSB programme and five students who use active learning instruction in the research design stage one whom were chosen randomly. Before the commencement of the interview, the researchers followed research ethics by providing a set of principles that assist them in conducting an ethically sounded study through obtaining students consent as well as assigning code to each participant in order to keep their identity confidential.

\section{Design and Development of ALuSB Programme}

In this research, the ALuSB programme was design using ADDIE model. ADDIE model is an instructional design model that is valid for any education; despite the fact that it comprises the components of all other design models, it is relatively a simple model $[37,38]$. Besides, numerous professional instructional designers have employed the general ADDIE framework [39] as a standard model for technology-based education as it is an instructional systems design model that presents a sequence of iterative steps for designing and developing effective training in five phases. The first phase is analysis while the second phase is design phase in which a Smart Board as a teaching and learning interactive tool was integrated with a model of active learning that yielded ALuSB programme to enhance HOTS in Data Handling. The third phase is development, the fourth phase is implementation, and lastly, the fifth phase is evaluation. To achieve the objectives of this research, the first stage of this research combines both quantitative and qualitative methods. The quantitative method was employed to identify the students' learning difficulties in each level of the cognitive domain in HOTS and also to identify the students' perceptions towards ALuSB programme in learning Data Handling. Meanwhile, the qualitative method is used to identify the methods used by students to learn HOTS in Data Handling as well as their perceptions towards the learning practices used in Data Handling.

\subsection{Phase I: Analysis}

This phase aims at analysing the students' learning difficulties in each level of the cognitive domain in HOTS in Data Handling before the design and development of the ALuSB programme. A study is piloted on the conventional learning method of Data Handling and the current students' learning difficulties in each level of the cognitive domain in HOTS in Malaysian primary school mathematics. A semi-structured interview with four experienced primary school mathematics teachers and year five students as well as exercise sheets analysis of the answers from the Data Handling school mathematics exercise sheets are carried out to detect the students' problems. The findings of the analysis provide an overview of the current method used in Data Handling and the current students' learning difficulties in each level of the cognitive domain in HOTS in Malaysian primary school mathematics.

\subsection{Phase II: Design}

The ALuSB programme was designed based on the dynamic structures of learning activities so as to facilitate active learning using a Smart Board to enhance HOTS in Data Handling. A model of active learning is used to design active learning instruction during the teaching and learning process of Data Handling which consists of set induction, step one, step two, step three and closure. Teachers can implement various active learning activities effectively and make learning meaningful for every student actively involved. By using a model of active learning in the ADDIE model to design the ALuSB programme, the Smart Board as a teaching and learning interactive tool was integrated with active learning. The learning content is organised and designed from lower to higher levels of cognitive processing according to the task and content analysis, as well as the learning objectives of this research.

\subsection{Phase III: Development}

The objective in this phase is to develop an ALuSB programme with the usage of a Smart Board to enhance HOTS in Data Handling in year five primary school mathematics. The teaching and learning activities were developed based on the Malaysian integrated curriculum for year five primary school mathematics which encompasses the following procedures: i) the development of understanding and applying the knowledge of average; ii) the development of understanding vocabulary relating to data organisation in graphs; iii) the development of organising and interpreting data from tables and charts.

\subsection{Phase IV: Implementation}

In this phase, the ALuSB programme was used by mathematics teachers who teach Data Handling in year five 
primary school mathematics. In order to achieve the research objectives, a plan for the implementation was prepared. The interactive lesson of the ALuSB programme is implemented for five weeks in the primary school. During the lessons in class for the first week, students and teachers tend to familiarise themselves with the use of the Smart Board. From the second week to the fifth week, the group implements the interactive lessons of the ALuSB programme during the mathematics lessons.

\subsection{Phase V: Evaluation}

This is the final phase that involves evaluating each step in order to make sure that the set goals are achieved [40]. The objective in this phase is to evaluate the effectiveness of the ALuSB programme in enhancing HOTS in Data Handling among students in a Malaysian primary school. It involves formative evaluation and summative evaluation.

\subsubsection{Formative Evaluation}

The formative evaluation is a series of informal and formal assessment events (which focuses on performance and the details of content) conducted by the teachers during students learning process in order to modify teaching and learning activities so as to increase student achievement. It also aims to see if the students understand the instruction before carrying out summative evaluation. The formative evaluation in this research involves 20 students, ten year five students who used the interactive lesson of the ALuSB programme in their learning and ten year five students who used the active learning instruction. The formative evaluation of the students focused on the usability of the ALuSB programme to enhance HOTS in Data Handling as well as the students learning experience. To test the validity of the respondents, responses to the open-ended questions, one-on-one interviews are conducted. Rubrics are used to determine the cognitive domain in HOTS (applying, analysing, evaluating, and creating) during the interview. All the students need to answer the pre-test and post-test as well as fill up the ALuSB programme evaluation form which uses a Likert scale measurement.

The time required by each student to answer the interview questions was about 20 minutes, the pre-test or post-test was an hour, and the ALuSB programme evaluation form was about 15 minutes. This information is important to enable the researchers in planning the time for the summative evaluation. Formative evaluations took about six weeks to be completed. Then, a week is used to refine the ALuSB programme. Additionally, ten experts are involved in the formative evaluation to validate the research instruments such as the ALuSB programme, ALuSB programme evaluation form, interview questions, pre-test and post-test, as well as a rubric for HOTS evaluation. Results of the formative evaluation from students and experts were used to improve the ALuSB programme.

\subsubsection{Summative Evaluation}

The summative evaluation is an assessment of samples where the emphasis is on the result of a program. It aims to summarise the overall learning at the completion of a program [41]. The research design used in this research to evaluate the effectiveness of the ALuSB programme in enhancing HOTS in Data Handling among students in a Malaysian primary school was based on qualitative and quantitative approaches with the combination of interviews and pre-test and post-test quasi-experimental design using nonequivalent control group. To achieve the objectives of the research, this research took eight weeks to be completed. The time interval between the pre-test and post-test is six weeks. The maturation problem is not a threat as the time interval between both tests is less than a year. Besides, the planning of the time interval is based on the Data Handling syllabus of the Malaysian integrated curriculum for year five primary school mathematics. It follows the school yearly lesson plan which requires around four weeks for teaching and learning Data Handling as well as the time interval between the pre-test and post-test was discussed with experts who have experience in conducting this type of research. The summative evaluation was carried out after the final version of the instruction was implemented in order to assess the overall effectiveness of the ALuSB programme in enhancing HOTS in Data Handling among students in a Malaysian primary school.

\section{Analysis of Findings}

In research design stage one, a semi-structured one-on-one interview was conducted by the researchers with students who used the ALuSB programme in order to investigate the use of ALuSB programme. Findings from the interview indicated that most of the students who used ALuSB programme shared similar interest on the features in the ALuSB programme. They highlighted that ALuSB programme made learning of Data Handling more fun and effective as compared to the traditional teaching. Knowledge and skills acquired during class could be successfully retained in memory. The data showed that students who used ALuSB programme were able to turn data to understandable information, as well as involve themselves in various interactive activities. The activities managed to train and help them to understand the concept of Data Handling.

In addition, the AluSB programme was validated by five experts in Mathematics. All the experts strongly agreed with the features of the ALuSB programme. The ALuSB programme encouraged students to participate in all the learning activities in the classroom. Students' discussion 
and presentation were promoted during lessons. Through the ALuSB programme, students were encouraged to makes efforts to complete all the learning activities in class. Furthermore, students were encouraged to have an internal dialogue in which they verbalised understanding. Besides, all the experts also strongly agreed that smart board played vital role in the ALuSB programme. Hence, a smart board allows students to experience a range of new learning tools which encourage engagement with course content, serving as an alternative to passively listening to a lecture or simply reading a text. The touch screen technology of smart board provides greater flexibility in the presentation of the materials. It provides ample workspace for hands-on activities with various multimedia resources, having a display surface huge enough to encourage high level of student interaction.

Next, in the second stage, pre-test and post-test were used to discuss the consequences of learning using the ALuSB programme, active learning instruction and conventional learning method in enhancing each level of the cognitive domain in HOTS in Data Handling among students. Table 1 shows the result of the analysis.

Table 1. Comparison of the mean score of each cognitive domain in HOTS between pretest and posttest among each student group

\begin{tabular}{|c|c|c|c|c|c|c|c|c|}
\hline \multirow{2}{*}{ Cognitive Domain } & \multicolumn{2}{|c|}{ Applying } & \multicolumn{2}{c|}{ Analysing } & \multicolumn{2}{c|}{ Evaluation } & \multicolumn{2}{c|}{ Creating } \\
\cline { 2 - 10 } Group & Pretest & Posttest & Pretest & Posttest & Pretest & Posttest & Pretest & Posttest \\
\hline Experimental group A & 4.43 & 7.57 & 3.43 & 7.23 & 2.23 & 6.70 & 1.20 & 6.73 \\
\hline Experimental group B & 4.33 & 6.70 & 3.50 & 5.57 & 2.20 & 4.83 & 1.27 & 4.47 \\
\hline Control group & 4.40 & 5.10 & 3.43 & 4.33 & 2.17 & 3.03 & 1.20 & 2.47 \\
\hline
\end{tabular}

Table 2. One-way anova for mean scores of the posttest

\begin{tabular}{|c|c|c|c|c|c|}
\hline & Sum of Squares & Df & Mean Square & F & Sig. \\
\hline Between Groups & 2640.156 & 2 & 1320.078 & 586.551 & .000 \\
Within Groups & 195.800 & 87 & 2.251 & & \\
Total & 2835.956 & 89 & & & \\
\hline
\end{tabular}

Table 3. Post hoc tests

\begin{tabular}{|cc|c|c|c|c|c|}
\hline \multicolumn{7}{|c|}{$\begin{array}{c}\text { Multiple Comparisons } \\
\text { Dependent Variable: Posttest } \\
\text { Tukey HSD }\end{array}$} \\
\hline \multirow{2}{*}{ (I) Group } & \multirow{2}{*}{$\begin{array}{c}\text { (J) Group } \\
\text { ALuSB }\end{array}$} & $\begin{array}{c}\text { Mean Difference } \\
(\mathrm{I}-\mathrm{J})\end{array}$ & Std. Error & Sig. & \multicolumn{2}{c|}{$95 \%$ Confidence Interval } \\
\cline { 3 - 7 } & Active learning & $6.700^{*}$ & .387 & .000 & 5.78 & 7.62 \\
Active & Control & $13.267^{*}$ & .387 & .000 & 12.34 & 14.19 \\
learning & ALuSB & $-6.700^{*}$ & .387 & .000 & -7.62 & -5.78 \\
& Control & $6.567^{*}$ & .387 & .000 & 5.64 & 7.49 \\
Control & ALuSB & $-13.267^{*}$ & .387 & .000 & -14.19 & -12.34 \\
\hline \multicolumn{2}{|c|}{ Active learning } & $-6.567^{*}$ & .387 & .000 & -7.49 & -5.64 \\
\hline
\end{tabular}


As shown in Table 1, the mean score of each cognitive domain in HOTS for the post-test among each student group was significantly higher than the pre-test which indicates improvement in HOTS in Data Handling among each student group. Experimental group A which used the ALuSB programme in learning Data Handling recorded the largest improvement in HOTS in Data Handling as experimental group A also has the largest difference on each cognitive domain in HOTS between pre-test and post-test, Applying $=3.14$, Analysing $=3.8$ Evaluating $=$ 4.47 , and Creating $=5.53$. On the other hand, control group which used the conventional learning method in learning Data Handling recorded the smallest improvement in HOTS in Data Handling as also the control group had the smallest difference on each cognitive domain in HOTS between pre-test and post-test.

ANOVA was used to evaluate mean differences between the treatments. Table 2 shows the analysis from one-way ANOVA for mean scores of post-test. The results indicates that there were significant differences (sig. value $=<0.000$ ) between the mean scores of post-test in the $95 \%$ confidence interval. The significance value was $<0.000$, which was below 0.05 and therefore, the null hypothesis was rejected and it could be concluded that there was a statistically significant treatment effect.

To determine precisely which mean differences were significant and which were not, a post hoc test was conducted. Table 3 shows the analysis from the post hoc tests in the $95 \%$ confidence interval. The results indicated that there was a statistically significant difference between all the treatments as all the significance value was $<0.000$, which was below 0.05 .

There was a statistically significant difference between groups as determined by one-way ANOVA $(\mathrm{F}(2,87)=$ $586.551, p=<0.000)$. The post hoc test revealed that there was a statistically significant difference between the ALuSB programme, active learning instruction and conventional learning method in enhancing HOTS in Data Handling among students in a Malaysian primary school $(p=<0.000)$.

Lastly, interviews were conducted with sudents to get an in-depth explanation of the improvement that resulted from the ALuSB programme learning. Findings from the interview indicated that majority of the students agreed that the ALuSB programme had motivated them to learn, helped to promote learning, encouraged HOTS, supported learning by doing, encouraged peer sharing as well as made learning more fun and interesting. Therefore, the ALuSB programme shows various positive attributes which can support students in enhancing HOTS in Data Handling. Table 4 shows the excerpts taken from interview data of students who used ALuSB programme.

Table 4. Excerpts from students on how ALuSB programme helped them in learning data handling

\begin{tabular}{|c|l|}
\hline \multicolumn{1}{|c|}{ Themes } & \multicolumn{1}{c|}{ Excerpts from Respondents } \\
\hline Highly motivated & i) Student A2: Learning activities in the ALuSB programme are highly motivating. \\
\hline Promotes learning & $\begin{array}{l}\text { i) Student A7: ALuSB programme improves my knowledge of Data Handling. } \\
\text { ii) Student A9: ALuSB programme improves my learning of Data Handling. } \\
\text { iii) Student A13: ALuSB programme is flexible and allows me to access all its content easily. }\end{array}$ \\
\hline $\begin{array}{c}\text { Learning } \\
\text { ownership }\end{array}$ & i) Student A12: Design of the ALuSB program promotes the ownership of my learning. \\
\hline Encourages HOTS & $\begin{array}{l}\text { i) Student A1: ALuSB programme remind me about the use of HOTS in my learning. } \\
\text { ii) Student A7: I always engage HOTS when I use ALuSB programme. } \\
\text { iii) Student A8: It provides tasks that enable me to improve and practice HOTS. } \\
\text { iv) Student A10: It uses appropriate tools during the learning to get me to think and reflect. } \\
\text { v) Student A13: ALuSB programme provides thinking tasks and exercises that enable me to improve HOTS. } \\
\text { vi) Student A16: ALuSB programme stimulates and encourages me in applying, analysing, evaluating and creating } \\
\text { (HOTS). }\end{array}$ \\
\hline Supports learning \\
by doing & $\begin{array}{l}\text { i) Student A2: ALuSB programme facilitates learning by doing. } \\
\text { ii) Student A7: It facilitates learning by designing and doing. } \\
\text { iii) Student A8: I can create my table and graph using the smart board. } \\
\text { iv) Student A20: I need to do a lot of activities during ALuSB programme when I learn Data Handling }\end{array}$ \\
\hline $\begin{array}{c}\text { Encourages peer } \\
\text { sharing }\end{array}$ & $\begin{array}{l}\text { i) Student A23: ALuSB programme allows me to share my learning. } \\
\text { ii) Student A28: It permit me to share my learning among peers. } \\
\text { iii) Student A29: Learning activities and group activities used in the ALuSB programme enable better understanding } \\
\text { of the concepts I learnt. }\end{array}$ \\
\hline enhances learning & $\begin{array}{l}\text { i) Student A12: The smart board has a huge touch screen whiteboard. Complicated data is turned into more vivid and } \\
\text { easy-to-understand visual images. } \\
\text { ii) Student A20: It enhances my enjoyment and enthusiasm during the Data Handling learning process. } \\
\text { iii) Student A22: The use of the smart board is easy and intuitive. }\end{array}$ \\
\hline
\end{tabular}




\section{Discussion}

\subsection{Design and Development of the ALuSB Programme}

Based on the findings from the interviews with students, majority of the students agreed that the use of active learning while learning Data Handling in class was more effective. This finding is consistent with the findings from studies in [42-45], that students prefer active learning than traditional lectures, and that such strategies are comparable to lectures in promoting mastery of content and superior in promoting HOTS. Thus, a model of active learning [37] is used to design active learning instruction during the teaching and learning process in this research. Each of the four modes of learning has its own value, when the modes of learning are connected properly, various learning activities can be interactive and thereby increase the educational effect. As noted by [46], as little as five minutes of active learning activities per fifty-minute class session can boost learning significantly. A model of active learning requires students' active participation, performing meaningful learning activities and think about what they are doing. Academically weak students get the benefit of being tutored by stronger classmates, at the same time stronger students get a deeper understanding while guiding weak students. Active learning is a prerequisite for effective and meaningful learning and achieving many academic and other outcomes, such as better critical thinking skills, openness to diversity, and growth in leadership and other job-related skills [47, 48].

Nonetheless, students also mostly agreed that the use of the smart board while learning Data Handling in class was more effective. Studies that examined the use of technology in schools and its effectiveness found that the use of technology is efficient for students [49]. Technology has also become part of the schools instructional process. Teachers need to facilitate students' understanding as nowadays technology plays a vital role on active learning in the classroom lesson [50]. This is in line with the findings from study of [51], that most students report that learning in a technological environment boosts their motivation and enhanced their learning experience. The major contribution of technology as perceived by students is in increasing access: to a variety of tools that contribute to understanding the study material, to organization of the information, to efficacy in carrying out assignments, and to development of knowledge. The use of smart boards in class has the potential to enhance students' knowledge and skills in Data Handling. As noted by ref [51], a smart board affords choices on various topics, developing knowledge, organising information, self-efficacy in carrying out assignments in a friendly environment, as well as to the representation of products that generate a sense of success, pleasure, and contribute to a more creative and higher standard learning product. Students claimed that the smart board encourages motivation to learn, raises the level of concentration, and has a strong effect on behaviour [52].

Teachers use smart boards to enhance lessons so that students become active learners in the class. It changes the students from having a passive role in learning to an active learning role that includes critical thinking skills [53]. A smart board creates an active learning environment for the students which promote their engagement in class. Ref [54] indicates that students with autism were engaged for up to 45 minutes compared to 15 minutes before the integration of smart boards. Similarly, ref [55] found that smart boards worked great in engaging kinaesthetic learners because students could get up and use manipulatives just by touching the screen than it got the students working on the smart board right up in front of the class. Visual learners as well became more motivated and engaged because of their use with the smart board. Students who did not understand a mathematics concept written as an equation better understood the concept when it was visually represented on the screen. These similar findings indicate that smart boards have a significant impact on students' learning and supports active learning. Thus, in order to enhance HOTS in Data Handling among students in a Malaysian primary school, smart board is integrated with active learning to develop the ALuSB programme.

\subsection{Effectiveness of the AluSB programme in enhancing HOTS in Data Handling}

The mean score of each cognitive domain in HOTS between pre-test and post-test among each student group as shown in Table 1 showed that there was an improvement of HOTS among the students. Experimental group A which used the ALuSB programme in learning Data Handling recorded the largest improvement in HOTS in Data Handling. Most of the students in experimental group A were unable to answer the questions that were designed to evaluate their HOTS before the ALuSB programme was introduced to them. However, after the students went through the learning of Data Handling with the ALuSB programme, they were more able to solve the HOTS questions correctly compared with the students who learn Data Handling using active learning instruction and conventional learning methods. This is indicated by the improvement of the mean scores of each cognitive domain in HOTS in the post-test. A smart board as an interactive technology tool facilitates students' learning practice and enhances their HOTS. Ref [56] reported a similar finding in which the interactivity in the classroom was influenced by students through the use of the smart board as the students role with the smart board change from viewer to active user. The results from the research were also consistent with studies in [57-59] whom stressed that students' HOTS can be improved when smart board is used as an efficient tool for orchestrating the interaction and lesson. Furthermore, the findings from the interviews with students also show 
that students are satisfied with their learning through the smart board. This finding is in line with the previous studies of [32], [60] whom pointed out that students are interested and enjoyed using smart board. They further ascertained that a smart board encourages students' active participation, makes the lessons more fun, as well as uses time efficiently to facilitate students' learning practices and enhances HOTS.

Besides, findings from the interviews with students which used the ALuSB programme in learning Data Handling also showed that most of the students agreed that the ALuSB programme possessed good design attributes in the ALuSB activities, presentation design, student's performance and student's HOTS achievement. The ALuSB programme provides students with a collaborative and active learning environment as well as shows solutions of various questions clearly and encourages student thinking. Students can enhance the understanding of Data Handling concepts throughout the active learning activities in the ALuSB programme. The use of active learning in learning Data Handling appears to be successful as it is increasing students' levels of satisfaction and enjoyment as well as reducing academic failure rates [61]. Active learning could promote students to engage in HOTS during the learning process. The finding is consistent with the results reported from studies in [62-65], that students' achievement in HOTS was increased by using active learning in class. Active learning helps students to ascend Bloom's Taxanomy from remembering and understanding to analysing and creating. Hence, it can be concluded that the ALuSB programme that was designed and developed by the researchers through integrating a smart board with active learning is capable of enhancing HOTS in Data Handling among primary school students.

\section{Conclusions}

In a nutshell, most of the teaching and learning of mathematics in primary schools emphasise the development of knowledge but not HOTS. Literature and research showed that HOTS is important to educate people to cope with the rapidly changing world. Various researchers claim the potential of technology to provide a technology-rich innovative learning environment for students to construct their knowledge while mastering more advanced thinking skills [66]. A smart board is among the top technological tools which have become widely used by numerous school teachers in different countries. While $90 \%$ of classrooms in Japan and the United States of America are adorned with smart boards, $70 \%$ of European Union classrooms have them [67, 68]. In Malaysia, the Ministry of Education introduced smart boards in 2004 and it has been widely used in primary schools. The integration of smart board into school lesson facilitates active learning, which is fundamental to the mastery of skills as well as enhances HOTS and students' learning. In the conventional leaning methods, students play a passive role and do not have an opportunity of constructing and reflecting their learning. These actions of constructing and reflecting their learning are via HOTS. Therefore, the smart board as a teaching and learning interactive tool is integrated with a model of active learning to design and develop the ALuSB programme in enhancing HOTS. The learning environment of the ALuSB programme acts: to engage in higher order activity, to encourage learners to construct their learning, and to reflect on the consequence of their thinking. Besides, the ALuSB programme provides step-by-step instruction that guides students to learn Data Handling using smart board with active learning. The activities in the ALuSB programme are very helpful for students to visualise all data in table, charts or graphs and translate it into real-world as the learning activities and tasks that are developed in the ALuSB programme are based on student's daily life. Also, the activities in the ALuSB programme are designed and developed to encourage students to think of levelling, understanding, conceptualising, applying, analysing, synthesising, and creating further evaluations in parallel with Anderson and Krathwohl's Revised Taxonomy [33]. Lastly, referring to the findings of this study, it is hoped that the findings of this research would be resourceful in offering an alternative for educators or researchers to design and develop technology-supported learning programmes using smart boards, especially for those who intend to enhance students' learning and HOTS.

\section{Acknowledgments}

The authors would like to thank the Ministry of Education and Universiti Teknologi Malaysia for their financial support. This work was supported by the UTMShine Grant no. Q.J130000.2413.09G34

\section{REFERENCES}

[1] Shaughnessy, J. M. (1992). Research in probability and statistics: Reflections and directions. In D. A.Grouws (Ed.), Handbook of research on mathematical teaching and learning (pp. 465-494). New York: Macmillan.

[2] Organisation for Economic Cooperation and Development. (OECD, 2013). PISA 2012 assessment and analytical framework: Mathematics, reading, science, problem solving and financial literacy. Paris: Author. Retrieved from http://www.oecd.org/pisa/pisaproducts/PISA\%202012\%20f ramework\%20e-book_final.pdf.

[3] TIMSS (2011). Trends in international mathematics and science study, International Associations for the Evaluation of Educational achievement, Retrieved from http://timss.bc.edu/timss2011/. 
[4] Curriculum Development Centre (CDC, 2006). Integrated curriculum for primary schools curriculum specifications mathematics year six. Kuala Lumpur: Ministry Of Education, Malaysia.

[5] Wenglinsky, H. (2002). How schools matter: The link between teacher classroom practices and student academic performance. Education Policy Analysis Archives, 10(12). Retrieved from http://epaa.asu.edu/ojs/article/view/291/417.

[6] Mohd-Ali, B. I. and Shaharom, B. N. (2003). Perbandingan pencapaian para pelajar dalam pentaksiran kerja amali dengan peperiksaan bertulis (Comparison of students' achievement in practical work assessment and written examination). Buletin PerSCATuan Pendidikan Sains dan Matematik Johor, 12(1), 14-27.

[7] Sulaiman, R. (2003). Pelaksanaan pendekatan pengajaran kemahiran berfikir dalam mata pelajaran sejarah: Satu kajian kes. Bangi: Universiti Kebangsaan Malaysia.

[8] Ng, A. K. (2004). Liberating the creative spirit in Asian students. Pearson Prentice Hall.

[9] Idris, N. (2010). Penyelidikan dalam Pendidikan. Malaysia: Mc Draw Hill (Malaysia) Sdn. Bhd.

[10] Zohar, A. (2013). Challenges in wide scale implementation efforts to foster higher order thinking (HOT) in science education across a whole wide system. Thinking Skills and Creativity, 10, 233-249.

[11] Malaysia Ministry of Education. (2012). Malaysia Education Blueprint 2013-2025: Preliminary report. Retrieved from http://www.moe.gov.my/userfiles/file/PPP/Preliminary-Blu eprint-Eng.pdf.

[12] Ivie, S. D. (1998). Ausubel's learning theory: An approach to teaching higher order thinking skills. The High School Journal, 35-42. Retrieved from http://ezproxy.um.edu.my:2057/stable/pdfplus/10.2307/403 64708.pdf?acceptTC $=$ true.

[13] Demirli, C. and Türel, Y. K. (2010). Instructional interactive whiteboard materials: Designers' perspectives, World Conference on Learning, Teaching and Educational Leadership, 9, 1437-1442.

[14] Malaysia Ministry of Education. (2004) Annual Report Ministry of Education 2004, Putrajaya: Ministry of Education Malaysia.

[15] Giles, R. M. and Shaw, E. L. (2011). SMART Boards rock. Science and children.

[16] Levy, P. and Partnership, S. E. I. C. (2002). Interactive whiteboards in learning and teaching in two Sheffield schools: a developmental study: Sheffield Excellence in Cities Partnership.

[17] Beeland, W. (2001). Student engagement, visual learning and technology: Can interactive whiteboards help?, Paper presented at Annual Conference of the Association of Information Technology for Teaching Education, Trinity College, Dublin.

[18] Holderied, A. C. (2011). Instructional design for the active: Employing interactive technologies and active learning exercises to enhance information literacy. Journal of Information Literacy, 5(1), 23-32. Retrieved from http://search.ebscohost.com/login.aspx?direct=trueanddb=li hand $\mathrm{AN}=65789106$ andsite $=$ ehost-liveandscope $=$ site .
[19] Guthrie, R. W. and Carlin, A. (2004). Waking the Dead: Using Interactive Technology to Engage Passive Listeners in the Classroom. Proceedings of the 10th Americas Conference on Information Systems, New York.

[20] Braxton, J. M., Jones, W. A., Hirschy, A. S. and Hartley, H. V., III. (2008). The role of active learning in college persistence. New directions for teaching and learning, number $115,71-83$.

[21] Prince, M. (2004). Does active learning work? A review of the research. Journal of Engineering Education, 93(3), 223231.

[22] Dee, L. and Fardanesh, H. (2010). A Classification of constructivist instructional design models based on learning and teaching approaches. Online Submission, 16. Retrieved from

http://www.ed.utah.edu/users/robert.zheng/6750reading/far danesh.pdf.

[23] Cohen, L., Manion, L. and Morrison, K. (2007). Research methods in education. New York: Routledge.

[24] Douglas C. (2001). Design and analysis of experiments (5th Ed.). New York: Wiley.

[25] Lynne J. W. and Herve, A. (2010). Post-hoc comparisons. Neil Salkind (Ed.), Encyclopedia of research design. Thousand Oaks, CA: Sage, 1-12.

[26] Attride-Stirling, J. (2001). Thematic networks: an analytic tool for qualitative research. Qualitative research, 1(3), 385-405.

[27] Howard, D. B. (2009). An assessment of interactive white boards in Lancaster community schools.

[28] Brame, C. (2016). Active learning. Vanderbilt University center for teaching. Retrieved from https://cft.vanderbilt.edu/active-learning/.

[29] Karin, K. H. (2013). Hess cognitive rigor matrix (CRM) in local assessment toolkit. Retrieved from http://www.uen.org/literacyresources/downloads/linking_re search_with_pra ctice.pdf.

[30] Kenneth, W. and Ellen, S. (2007). The role of rubrics in advancing and assessing student learning. The journal of effective teaching, 7(1), 3-14. Retrieved from http://works.bepress.com/cgi/viewcontent.cgi? article $=1058$ andcontext $=$ susa $n \_$madsen\#page $=8$.

[31] Stiggins, R. (2001). Student-involved classroom assessment (3rd Ed.). New York: Merrill.

[32] Hafner, J. C. and Hafner, P. M. (2004). Quantitative analysis of the rubric as an assessment tool: An empirical study of student peer-group rating. International Journal of Science Education, 25(12), 1509-1528.

[33] Anderson, L. and Krathwohl, D. (2001). A taxonomy for learning, teaching, and assessing: A revision of bloom's taxonomy of educational objectives. New York, NY: Longman Publishing Co.

[34] Annabel, B. K. (2005). Using interviews as research instruments. E-journal for researching teachers, 2, 41-52. Retrieved from http://www.culi.chula.ac.th/research/publications/4. 
[35] Costa, A. L. and Kallick, B. (2001). Building a system for assessing thinking. In Costa. A. L. Ed. Developing minds: A recourse book for teaching thinking (3rd Ed.). Alexandria, Virginia: Association for supervision and curriculum development, pp. 517-527.

[36] Boyce, C. and Neale, P. (2006). Conducting in-depth interviews: A guide for designing and conducting in-depth interviews. Pathfinder international tool series.

[37] Muhammad, S. A., Abdullah, A. H. and Osman, S. (2020). Design and development of linear algebra peer tutoring strategy to develop students mathematical thinking processes based on experts' evaluation. Universal journal of educational research; 8(8), 3592-3607. Doi: 10.13189/ujer.2020.080836

[38] Kaminski, J. (2007). Use ADDIE to design online courses. Retrieved from http://www.nursinginformatics.com.

[39] Morrison, G. R. (2010). Designing effective instruction (6th Ed.). John Wiley and Sons, Hoboken, New Jersey.

[40] Muhammad, S. A., Abdullah, A. H. and Osman, S. (2020). Developing mathematical thinking among polytechnic students in linear algebra through peer tutoring strategy. Journal of advanced research in dynamical and control systems, 12(3), 423-434. Doi: 10.5373/JARDCS/V12I3/20201210.

[41] Glickman, C. D., Gordon, S. P. and Ross-Gordon, J. M. (2009). Supervision and instructional leadership: A developmental approach. Boston, MA: Allyn and Bacon.

[42] Staley, C. C. (2003). 50 Ways to leave your lectern: Active learning strategies to engage first-year students.

[43] Fox, M. A. and Hackerman, N. (Eds.). (2003). Evaluating and improving undergraduate teaching in sciences, technology, engineering, and mathematics. Washington, DC: National academies press.

[44] Bain, K. (2004). What the best college teachers do. Cambridge: Harvard University Press.

[45] McKeachie, W. J. and Svinicki, M. (2006). Teaching tips: strategies, research, and theory for College and University teachers. Belmont, CA: Wadsworth.

[46] Felder, R. M. and Brent, R. (2003). Learning by doing. Chemical engineering education. 37:4. Retrieved from http://www4.ncsu.edu/unity/lockers/users/f/felder/public/C olumns/Active.pdf.

[47] Miller, R. L., Amsel, E., Marsteller Kowalewski, B., Beins, B. C., Kenneth, D. K. and Peden, B. F. (Eds.). (2011). Promoting student engagement, Volume 1: Programs, techniques and opportunities, society for the teaching of psychology: American psychological association. Retrieved from http://teachpsych.org/ebooks/pse2011/vol1/index.php.

[48] Smith, K. A., Sheppard, S. D., Johnson, D. W. and Johnson, R. T. (2005). Pedagogies of engagement: Classroom-based practices. Journal of engineering education, 94(1), 87-101. DOI: 10.1002/j.2168- 9830.2005.tb00831.x.

[49] Anderson, R. E. and Dexter, S. (2005). School technology leadership: An empirical investigation of prevalence and effect. Educational administration quarterly, 41(1), 49-82. Retrieved from https://doi.org/10.1177/0013161X04269517.
[50] Jacobs, H. (2010). Curriculum 21: Essential education for a changing world. Alexandrai, VA: Association for supervision and curriculum development.

[51] Dori, S. and Kurtz, G. (2015). Student's perceptions meaningful learning via ICT. Paper presented at the 2015 Chais Annual Meeting, Open University, Raanana.

[52] Schuck, S. and Kearney, M. (2007). Exploring pedagogy with interactive whiteboards: A case study of six schools. Sydney: Sydney University of Technology.

[53] Auerbach, A. (2012). Teaching diversity: Using a multifaceted approach to engaging students. PS: Political science and politics, 45(3), 516-520. DOI: $10.1017 / \mathrm{S} 1049096512000406$.

[54] McClaskey, K. and Welch, R. (2009). Whiteboards engage autistic students. Learning and leading with technology, 30-31.

[55] Eaton, C. (2005). Sparking a revolution in teaching and learning. The Journal, 33 (1), 20-24.

[56] Beauchamp, G. and Kennewell, S. (2010). Interactivity in the classroom and its impact on learning. Computers and education, 54(3), 759-766.

[57] Jones, P., Kervin, L. and McIntosh, S. (2011). The interactive whiteboard: Tool and/or agent of semiotic mediation. Australian journal of language and literacy, 34(1), 38-60. Retrieved from http://www.akea.edu.au/resources/A JU.

[58] Tenneille, T. L. (2012). Interactive whiteboard use: The catalyst of student achievement dissertations. 711. Retrieved from https://aquila.usm.edu/dissertations/711.

[59] BECTA. (2008). Harnessing technology schools survey 2007: Analysis and key findings. Retrieved from http://partners.becta.org.uk/uploaddir/downloads/page_doc uments/research/ht_schools_survey07_key_findings.pdf.

[60] Lewin, C., Somekh, B. and Steadman, S. (2008). Embedding interactive whiteboards in teaching and learning: The process of change

[61] Freeman, S., Eddy, S. L., McDonough, M., Smith, M. K., Okoroafor, N. and Jordt, H., et al. (2014). Active learning increases student performance in science, engineering, and mathematics. Proc. Natl. Acad. Sci. U.S.A. $1118410-8415$. 10.1073/pnas. 1319030111

[62] Ann, K. and Jim, M. (2003). Active Learning exercises requiring Higher-Order Thinking Skills.

[63] Noor Suhaily, M., Muhammad, S. A., Abdullah, A. H., Osman, S., Mohd Hilmi, H. and Ahmad, F. (2020). Enhancing students' higher-order thinking skills (hots) through an inductive reasoning strategy using Geogebra. International journal of emerging technologies in learning; 15(3), 156-179.

[64] Handelsman, J. O., Sarah, M. and Christine, P. (2007). Scientific teaching. Madison, WI: Wisconsin program for scientific teaching.

[65] Muhammad, S. A., Abdullah, A. H., Shamsuddin, N. S., Abd Rahman, S. N. S., Ashari, Z. M., Jumaat, N. F., Abu-Samah, N. and Ali, D. F. (2020). Pupil's behaviour pattern and non-routine mathematical problem-solving strategy based 
on multiple intelligences. JARDCS; 12(3), 466-485. Doi: 10.5373/JARDCS/V12I3/20201214

[66] Groff, J. (2014). Technology-rich innovative learning environments. OECD working paper.

[67] Buket, A. and Semra, E. (2013). A study on student and teacher views on technology use. Procedia - social and behavioral sciences 103: 68-76. Retrieved from http://dx.doi.org/10.1016/j.sbspro.2013.10.309.

[68] Abdullah, A. H., Ibrahim, N. H., Surif, J., Ali, M. and Hamzah, M. H. (2015). Non-routine mathematical problems among in-service and pre-service mathematics teachers. (2015) Proceedings of IEEE International Conference on Teaching, Assessment and Learning for Engineering: Learning for the Future Now, TALE 2014, pp. 18-24. DOI: 10.1109/TALE.2014.7062620 